\title{
Simulation of heat distribution in the human eye using discontinuous dual reciprocity boundary element method and non-overlapping domain decomposition approach
}

\author{
Ahmedou Bamba S., Ellabib A., El Madkouri A. \\ Université Cadi Ayyad, Laboratoire de Mathématiques Appliquées et Informatique, \\ Faculté des Sciences et Techniques, \\ Avenue Abdelkrim El Khattabi B. P. 549, Marrakesh, Morocco
}

(Received 15 October 2019; Revised 21 November 2019; Accepted 22 November 2019)

\begin{abstract}
In this work, a numerical bi-dimensional simulation of heat distribution in the human eye is investigated. A dual reciprocity boundary element method (DRBEM) is applied to obtain the heat distribution in the human eye. The non-overlapping Dirichlet-Neumann domain decomposition method combined with DRBEM is used to find a more accurate representation of heat distribution in the human eye presented for two, three and four subdomains. The result obtained are compared with literature experimental and numerical studies. The simulations of proposed algorithms describe with sufficient accuracy the heat distribution in the human eye.
\end{abstract}

Keywords: heat distribution, human eye, dual reciprocity method, boundary element method.

2010 MSC: $65 \mathrm{~N} 38,92 \mathrm{C} 50$

DOI: $10.23939 / \mathrm{mmc} 2020.01 .001$

\section{Introduction}

The human being is a homeothermic organism, which means that its body temperature is almost constant which is mainly attributed to the existence of the epidermal envelope, the skin. The skin is the first barrier to protect the human body. There is no epidermal envelope to protect the human eye from environmental fluctuations. The human eye is exposed to the temperature of the environment most of the time.

At the end of the 19th century, researchers became interested in the thermal profile of the human eye. At present, the measurement techniques initially used have been abandoned because of their devastating procedures for the human eye. In the early of 1960s, the development of modern technologies, especially the use of infra-red devices, made it possible to obtain measurements of temperature on the surface of the cornea without damaging the human eye. Erfon et al [5] used infra-red techniques and obtained a mean temperature of $34.3^{\circ} \mathrm{C}$, while Purslow et al [16] recorded a mean temperature of $35 \pm 1.1^{\circ} \mathrm{C}$. These infra-red techniques induce measurement errors and present only the measurements of the temperature on the corneal surface without giving any information on the temperature in other components of the eye.

During the last decades, with the availability of high computing power, numerical and mathematical investigations are considered by many researchers as an alternative to experimental techniques. In 1982, Lagendijk [10] using finite difference method (FDM) reported a mean corneal surface temperature of $34.5^{\circ} \mathrm{C}$. Later, Scott [18] used a finite element method (FEM) and obtained a temperature of $33.25^{\circ} \mathrm{C}$ at the surface of the cornea. $\mathrm{Ng}$ et al [13] obtained results of the ocular surface temperature using finite element method (FEM) to have a mean of $33.65^{\circ} \mathrm{C}$. In 2007 , Ooi et al [14] studied the bioheat transfer in the eye using boundary element method (BEM) and reported a mean corneal surface temperature of $33.68^{\circ} \mathrm{C}$. 
In this paper a discontinuous dual reciprocity boundary element method is adopted for the approximation of heat distribution in the human eye. This work is divided into five sections, in the first one the governing equation of heat distribution in human eye is presented with adequate boundary conditions, next part is devoted to the description of the combination of dual reciprocity method and non overlapping domain decomposition method [2], the forth section give a numerical application of the proposed methods to the investigated problem, finally some conclusions are drawn in the last section.

\section{The human eye model}

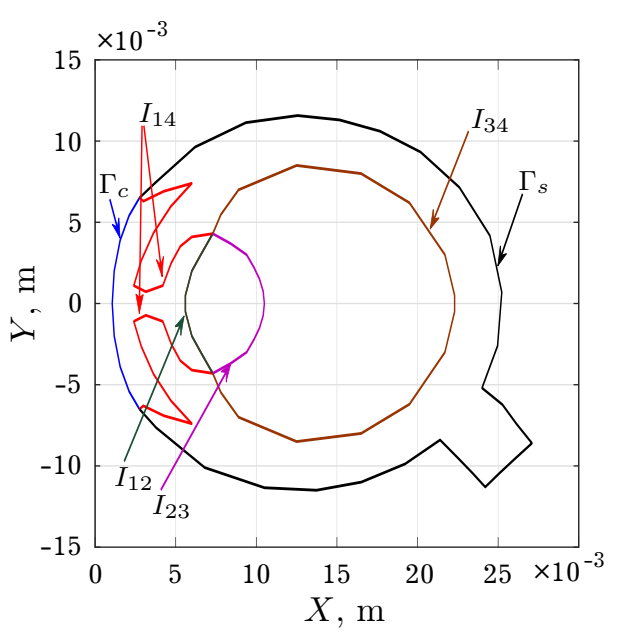

Fig. 1. 2D model of the human eye.

We developed a two-dimensional model of the human eye following closely the dimensions in the model in [13]. The human eye is modeled based on anatomical measurements reported in the literature [3,7]. The human eye is divided into four regions the aqueous humor, the lens, the vitreous humor and the sclera. The retina and the choroid are relatively very thin therefore, they are modeled as part of the sclera. The iris and the sclera have the same thermal properties and are modeled together. The cornea is assumed to be part of the aqueous humor since they both have similar thermal properties [4].

The human eye is modeled as comprising four domains, namely the aqueous humor, the lens, the vitreous humor and the sclera which we denote as $D_{1}, D_{2}, D_{3}$ and $D_{4}$, respectively as in Figs. 1 and 2. Thermal properties for each region of the human eye are given in Table 1.
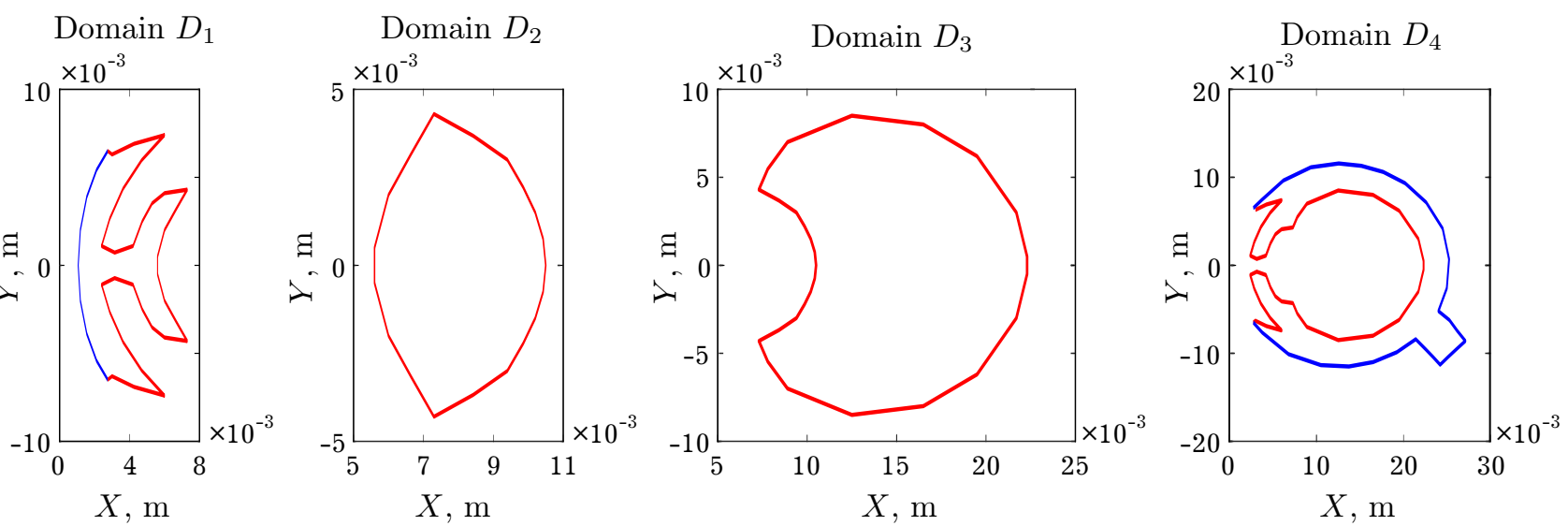

Fig. 2. Four sub-domains of the human eye $D_{1}, D_{2}, D_{3}$ and $D_{4}$.

Table 1. Characteristics of different tissues of the human eye.

\begin{tabular}{lccc}
\hline Tissue & $\begin{array}{c}\text { Thermal conductivity } \\
\left(\mathrm{W} \mathrm{m}^{-1} \mathrm{~K}^{-1}\right)\end{array}$ & \multicolumn{2}{c}{$\begin{array}{c}\text { Rate of blood } \\
\text { perfusion }\end{array}$} \\
Cornea & 0.58 & 0 \\
Aqueous humor & 0.58 & 0 \\
Lens & 0.40 & 0 \\
Iris & 1.0042 & 0 \\
Vitreous humor & 0.603 & 0 \\
Choroid & 0.53 & 0.021 \\
Retina & 0.565 & 0.035 \\
Sclera & 1.0042 & 0 \\
\hline
\end{tabular}




\section{Governing equations}

\subsection{Heat transfer equation}

The partial differential equation governing this simulation is the Pennes bioheat equation [15] and its is written as follows

$$
\rho c_{b} \frac{\partial T}{\partial t}=\nabla\left(k_{t} \nabla T\right)+\omega_{b} \rho_{b} c_{b}\left(T_{b}-T\right)+Q+Q_{m},
$$

where $\rho$ is the density $\left(\mathrm{kg} \mathrm{m}^{-3}\right), c_{b}$ is the specific temperature $\left(\mathrm{J} \mathrm{kg}^{-1} \mathrm{~K}^{-1}\right), k$ is the thermal conductivity of local tissue $\left(\mathrm{W} \mathrm{m}^{-1} \mathrm{~K}^{-1}\right), \omega_{b}$ is the rate of blood perfusion in the eye $(1 / \mathrm{s}), t$ is time $(s), Q_{m}$ is heat generated through metabolism $\left(\mathrm{W} \mathrm{m}^{-3}\right)$ and $Q$ is heat generated from external sources such as radiation. Subscript $t$ and $b$ refers to tissue and blood, respectively.

Heat generated by metabolism or by external source is neglected because the human eye is composed mainly of water and we assume that there is no radiations affecting the heat in human eye. For a steady state case, the equation (1) is written

$$
\nabla\left(k_{t} \nabla T\right)+\omega_{b} \rho_{b} c_{b}\left(T_{b}-T\right)=0 .
$$

The thermal conductivity of each sub-domain can be found in Table 1.

Moreover, $T_{b}$ is the blood temperature $37^{\circ} \mathrm{C}, C_{b}$ is the specific heat of blood $3594 \mathrm{~J} / \mathrm{kg}^{\circ} \mathrm{C}$ and $\rho_{b}$ is the density of blood which are equal to and $1060 \mathrm{~kg} / \mathrm{m}^{3}$.

\subsection{Boundary conditions}

Boundary conditions are defined on the cornea and the sclera as follow:

- On the sclera $\Gamma_{s}$, the blood flow is acting as a heating source

$$
-k \frac{\partial T}{\partial n}=h_{b l}\left(T-T_{b l}\right)
$$

In the above equation, $n$ is the normal direction to the surface boundary. $h_{b l}$ is the convection coefficient between blood and eye $\left(65 \mathrm{~W} \mathrm{~m}^{-2} \mathrm{~K}^{-1}\right)$ and $T_{b l}$ is blood temperature $\left(37^{\circ} \mathrm{C}\right)$.

- On the cornea $\Gamma_{c}$, where there are three forms of heat loss through convection, radiation and tears evaporation.

$$
-k \frac{\partial T}{\partial n}=h_{a m b}\left(T-T_{a m b}\right)+\sigma \varepsilon\left(T^{4}-T_{a m b}^{4}\right)+E .
$$

In this equation, $T_{a m b}$ is the ambient temperature $\left(25^{\circ} \mathrm{C}\right), h_{a m b}$ is the convection coefficient $\left(10 \mathrm{~W} \mathrm{~m}^{-2} \mathrm{~K}^{-1}\right)$ and $E$ is the tear evaporation rate of the eye $\left(40 \mathrm{~W} \mathrm{~m}^{-2}\right) . \sigma$ is the Stefan Boltzmann constant $\left(5.67 \times 10^{-8}, \mathrm{~W} \mathrm{~m}^{-2} \mathrm{~K}^{-4}\right)$ and $\varepsilon$ is emissivity 0.975 .

\section{Approximation methods}

In this section, a numerical solution of the problem (2) subject to (3) and (4) is investigated, where a boundary element approach is adopted.

\subsection{Discontinuous dual reciprocity boundary element method}

In order to develop an integro-differential equation of the considered problem with respect to regions $D_{i}$ (as illustrated in Fig. 2) a dual reciprocity boundary element method is adopted, i.e.,

$$
\begin{aligned}
\lambda(x, y) T_{i}(x, y)= & \int_{\Gamma_{i}} T_{i}(s, t) \frac{\partial T^{*}}{\partial n}(s, t ; x, y) d S(s, t)-\int_{\Gamma_{i}} T^{*}(s, t ; x, y) \frac{\partial T_{i}}{\partial n}(s, t) d S(s, t) \\
& +\int_{D_{i}} T^{*}(s, t ; x, y)\left[\frac{w_{b} \rho_{b} c_{b}}{k_{i}}\left(T_{b}-T_{i}\right)\right] d D(s, t)
\end{aligned}
$$


For $(s, t) \in D_{i} \cup \Gamma_{i}$ and $i=1,2,3$ and 4 . And the jump term is given as:

$$
\lambda(s, t)= \begin{cases}1, & (s, t) \in D_{i} \\ 0.5, & (s, t) \in \Gamma_{i} \\ 0, & \text { if not. }\end{cases}
$$

The fundamental solution $T^{*}(s, t ; x, y)$ is written as follows:

$$
T^{*}(s, t ; x, y)=-\frac{1}{2 \pi} \log \left(\sqrt{\left((x-s)^{2}+(y-t)^{2}\right)}\right)
$$

The next step is devoted to the discretization of the boundaries $\Gamma_{i}$ into $N_{i}$ elements, where for each element $\Gamma_{i}^{(j)}$ two points $\left(x_{i}^{(j)}, y_{i}^{(j)}\right)$ and $\left(x_{i}^{\left(N_{i}+j\right)}, y_{i}^{\left(N_{i}+j\right)}\right)$ are chosen accordingly to the following expressions:

$$
\begin{gathered}
\left(x_{i}^{(j)}, y_{i}^{(j)}\right)=\left(s_{i}^{(j)}, t_{i}^{(j)}\right)+\tau\left(s_{i}^{(j+1)}-s_{i}^{(j)}, t_{i}^{(j+1)}-t_{i}^{(j)}\right), \\
\left(x_{i}^{\left(N_{i}+j\right)}, y_{i}^{\left(N_{i}+j\right)}\right)=\left(s_{i}^{(j)}, t_{i}^{(j)}\right)+(1-\tau)\left(s_{i}^{(j+1)}-s_{i}^{(j)}, t_{i}^{(j+1)}-t_{i}^{(j)}\right),
\end{gathered}
$$

where the two points $\left(s_{i}^{(j)}, t_{i}^{(j)}\right)$ and $\left(s_{i}^{(j+1)}, t_{i}^{(j+1)}\right)$ denotes the ends points of the element $\Gamma_{i}^{(j)}$ respectively for $j=1,2, \ldots, N_{i}$, and $\left.\tau \in\right] 0,0.5$. We perform a linear approximation of the temperature and the heat flux (denoted $Q_{i}(s, t)$ ) in the following form:

$$
\begin{aligned}
& T_{i}(s, t) \simeq\left[1-d_{i}^{(j)}(s, t)\right] T_{i}^{(j)}+d_{i}^{(j)}(s, t) T_{i}^{\left(N_{i}+j\right)}, \\
& Q_{i}(s, t) \simeq\left[1-d_{i}^{(j)}(s, t)\right] Q_{i}^{(j)}+d_{i}^{(j)}(s, t) Q_{i}^{\left(N_{i}+j\right)},
\end{aligned}
$$

where

$$
d_{i}^{(j)}(s, t)=\frac{\sqrt{\left(s-s_{i}^{(j)}\right)^{2}+\left(t-t_{i}^{(j)}\right)^{2}}-\tau l_{i}^{(j)}}{(1-2 \tau) l_{i}^{(j)}}
$$

$T_{i}^{(j)}$ and $T_{i}^{\left(N_{i}+j\right)}$ denotes the temperature at the points $\left(x_{i}^{(j)}, y_{i}^{(j)}\right)$ and $\left(x_{i}^{\left(N_{i}+j\right)}, y_{i}^{\left(N_{i}+j\right)}\right)$ respectively, and $Q_{i}^{(j)}$ and $Q_{i}^{\left(N_{i}+j\right)}$ denotes the heat flux at the points $\left(x_{i}^{(j)}, y_{i}^{(j)}\right)$ and $\left(x_{i}^{\left(N_{i}+j\right)}, y_{i}^{\left(N_{i}+j\right)}\right)$ respectively, $l_{i}^{(j)}$ is the length of the element $\Gamma_{i}^{(j)}$.

The task of taking the domain integral in (5) to the boundary is achieved by using a radial basis function approximation of the integrand, in other words we have

$$
\left[\frac{w_{b} \rho_{b} c_{b}}{k_{i}}\left(T_{b}-T_{i}(s, t)\right)\right] \simeq \sum_{j=1}^{2 N_{i}+L_{i}} \alpha^{(j)} R^{(j)}\left(s, t ; s^{(j)}, t^{(j)}\right)
$$

where $L_{i}$ is the number of internal collocation points in the domain $D_{i}$ and the radial basis function $R^{(j)}(s, t)$ is given by $R^{(j)}\left(s, t ; s^{(j)}, t^{(j)}\right)=1+\left(\left(s-s^{(j)}\right)^{2}+\left(t-t^{(j)}\right)^{2}\right)+\left(\left(s-s^{(j)}\right)^{2}+\left(t-t^{(j)}\right)^{2}\right)^{3 / 2}$. The particular solution $\hat{T}$ and the radial basis function are related throw the following relation:

$$
\Delta \hat{T}=R
$$

Hence the system (5) can be written as follows

$$
\begin{aligned}
\lambda\left(x^{(p)}, y^{(p)}\right) T_{i}^{(p)}= & \sum_{k=1}^{N_{i}} H_{1 i}^{(k)}\left(x^{(p)}, y^{(p)}\right) T_{i}^{(k)}+H_{2 i}^{(k)}\left(x^{(p)}, y^{(p)}\right) T_{i}^{\left(N_{i}+k\right)} \\
& -G_{1 i}^{(k)}\left(x^{(p)}, y^{(p)}\right) Q_{i}^{(k)}-G_{2 i}^{(k)}\left(x^{(p)}, y^{(p)}\right) Q_{i}^{\left(N_{i}+k\right)} \\
= & \sum_{j=1}^{2 N_{i}+L_{i}} \sum_{k=1}^{N_{i}} H_{1 i}^{(k)}\left(x^{(p)}, y^{(p)}\right) T_{i}^{(k)}+H_{2 i}^{(k)}\left(x^{(p)}, y^{(p)}\right) T_{i}^{\left(N_{i}+k\right)}
\end{aligned}
$$

Mathematical Modeling and Computing, Vol. 7, No.1, pp. 1-13 (2020) 


$$
\begin{aligned}
& -G_{1 i}^{(k)}\left(x^{(p)}, y^{(p)}\right) Q_{i}^{(k)}-G_{2 i}^{(k)}\left(x^{(p)}, y^{(p)}\right) Q_{i}^{\left(N_{i}+k\right)} \\
& \quad \times \sum_{e=1}^{2 N_{i}+L_{i}} W_{i}^{(j e)}\left[\frac{w_{b} \rho_{b} c_{b}}{k_{i}}\left(T_{b}-T_{i}^{(j)}\right)\right]
\end{aligned}
$$

for $p=1,2, \ldots, 2 N_{i}+L_{i}$ and $i=1,2,3$ and 4 . Where $W_{i}^{(j e)}$ are the coefficients of the inverse of the matrix $R_{i}$. The system (8) constitutes $2 N_{i}$ unknown (the temperature) and $L_{i}$ internal unknown $T_{i}^{(p)}$ for $p=2 N_{i}+1, \ldots, 2 N_{i}+L_{i}$.

The line integrals $H_{1 i}^{(k)}, H_{2 i}^{(k)}, G_{1 i}^{(k)}$ and $G_{2 i}^{(k)}$ are defined by

$$
\begin{aligned}
& H_{1 i}^{(k)}(x, y)=\int_{\Gamma^{k}}\left(1-d_{i}^{(k)}\right) \frac{\partial T^{*}}{\partial n}(s, t ; x, y) d S \\
& H_{2 i}^{(k)}(x, y)=\int_{\Gamma^{k}} d_{i}^{(k)} \frac{\partial T^{*}}{\partial n}(s, t ; x, y) d S \\
& G_{1 i}^{(k)}(x, y)=\int_{\Gamma^{k}}\left(1-d_{i}^{(k)}\right) T^{*}(s, t ; x, y) d S \\
& G_{2 i}^{(k)}(x, y)=\int_{\Gamma^{k}} d_{i}^{(k)} T^{*}(s, t ; x, y) d S
\end{aligned}
$$

The non-linearity in (4) is treated using a non-linear modified Newton method with a given precision $10^{-15}$.

$$
-k \frac{\partial T}{\partial n}=h_{a m b}\left(T-T_{a m b}\right)-\sigma \varepsilon T_{a m b}^{4}+E .
$$

The given initial approximation is obtained by solving the linear system with using the previous linear boundary condition (8) instead of non-linear condition (4).

\subsection{Domain decomposition techniques}

In this part a non-overlapping Dirichlet-Neumann domain decomposition method is described, in the first case we decompose the human eye into two sub-domains, then three sub-domains case is investigated, and the last case is devoted to four sub-domains decomposition.

\subsubsection{The eye divided into two sub-domains}

The first domain decomposition technique is done by decomposing the human eye into two disjoint subdomains $D_{1} \cup D_{2}$ and $D_{3} \cup$ $D_{4}$ illustrated in Fig. 3. $I_{14}$ and $I_{23}$ are the interfaces between sub-domains $D_{1}$ and $D_{4}$ and $D_{2}$ and $D_{3}$, respectively. The DirichletNeumann algorithm used to solve problem (2)-(4) in two sub-domains is given by Algorithm 1.
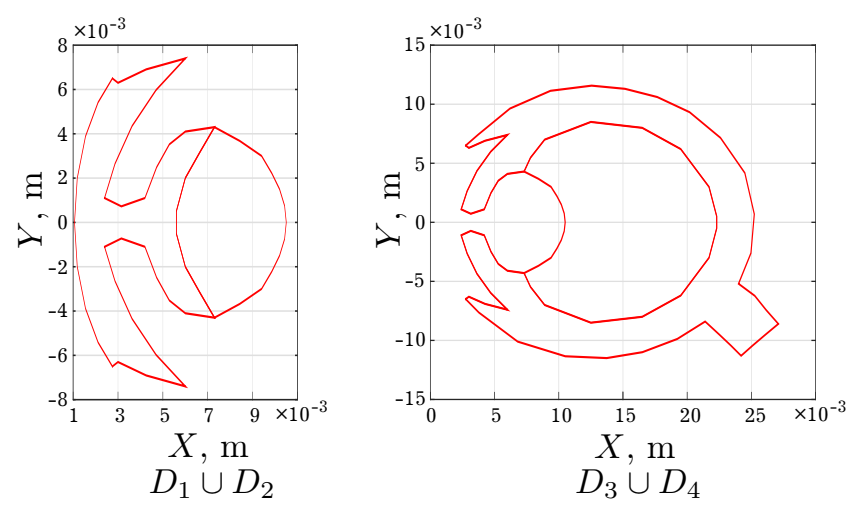

Fig. 3. The decomposition of the human eye into two subdomains. The first subdomain is $D_{1} \cup D_{2}$ composed of the cornea and the lens and the second subdomain $D_{3} \cup D_{4}$ is constitued of the iris, the vitreous humor and the sclera. 
Algorithm 1 Two non-overlapping subdomains

Tol, $\mu_{0}, k=1$, and error $=1$

While error $\geqslant$ Tol

- Solve non-linear problem (10) to obtain $\frac{\partial T_{1}^{k}}{\partial n_{1}}$ on $I_{14} \cup I_{23}$ :

$$
\left\{\begin{array}{l}
-\nabla\left(k_{1} \nabla T_{1}^{k}\right)+\omega_{b} \rho_{b} c_{b} T_{1}^{k}=\omega_{b} \rho_{b} c_{b} T_{b} \quad \text { in } D_{1} \cup D_{2}, \\
-k_{1} \frac{\partial T_{1}^{k}}{\partial n_{1}}=h_{a m b}\left(T_{1}^{k}-T_{a m b}\right)+\sigma \varepsilon\left(\left(T_{1}^{k}\right)^{4}-T_{a m b}^{4}\right)+E \quad \text { on } \Gamma_{c}, \\
T_{1}^{k}=\mu_{k-1} \quad \text { on } \quad I_{14} \cup I_{23} .
\end{array}\right.
$$

- Solve linear problem (11) to obtain $T_{2}^{k}$ on $I_{14} \cup I_{23}$ :

$$
\left\{\begin{array}{l}
-\nabla\left(k_{2} \nabla T_{2}^{k}\right)+\omega_{b} \rho_{b} c_{b} T_{2}^{k}=\omega_{b} \rho_{b} c_{b} T_{b} \quad \text { in } \quad D_{3} \cup D_{4}, \\
-k_{2} \frac{\partial T_{2}^{k}}{\partial n_{2}}=h_{b l}\left(T_{2}^{k}-T_{b l}\right) \quad \text { on } \quad \Gamma_{s}, \\
-k_{2} \frac{\partial T_{2}^{k}}{\partial n_{2}}=k_{1} \frac{\partial T_{1}^{k}}{\partial n_{1}} \quad \text { on } \quad I_{14} \cup I_{23} .
\end{array}\right.
$$

- Update:

$$
\left.\mu_{k}=\mu_{k-1}+\theta\left(T_{2}^{k}-\mu_{k-1}\right) \quad \text { on } \quad I_{14} \cup I_{23} \quad \text { and } \quad \theta \in\right] 0,1[
$$

- Compute:

$$
\text { error }=\left\|\mu_{k}-\mu_{k-1}\right\|, \quad k=k+1 .
$$

End while

\subsubsection{The eye divided into three sub-domains}

The human eye is decomposed into three sub-domains $D_{1}, D_{2}$ and $D_{3} \cup D_{4}$, shown in Fig. $4 . I_{12}$ and $I_{14}$ are the interfaces between sub-domains $D_{1}$ and $D_{2}$ and $D_{1}$ and $D_{4}$, respectively. $I_{23}$ refers to the interface between sub-domains $D_{2}$ and $D_{3}$. The Dirichlet-Neumann algorithm solving problem (2)-(4) is written as in Algorithm 2.

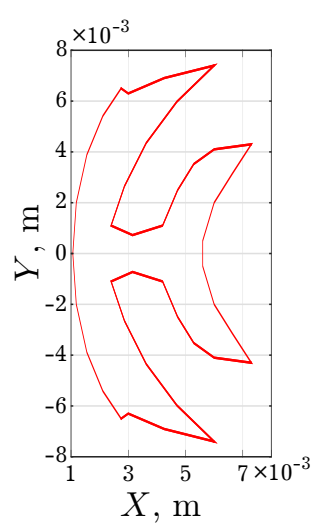

$D_{1}$

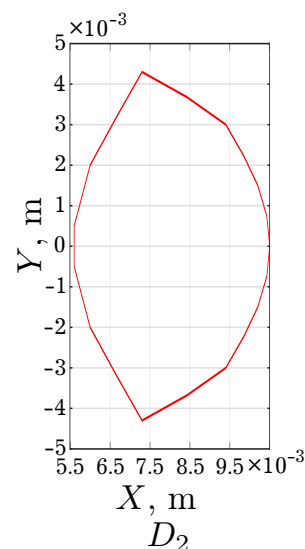

$D_{2}$

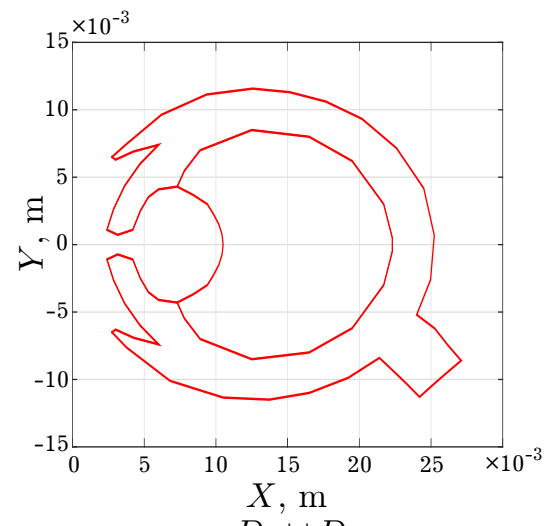

$D_{3} \cup D_{4}$

Fig. 4. The decomposition of the human eye into three subdomains. The first subdomain is $D_{1}$ composed of the cornea and the aqueous humor, the second subdomain $D_{2}$ is the lens and the third subdomain $D_{3} \cup D_{4}$ is constitued of the iris, the vitreous humor and the sclera. 
Algorithm 2 Three non-overlapping subdomains

Tol, $\mu_{0}^{1}, \mu_{0}^{2}, k=1$, and error $=1$

While error $\geqslant T o l$

- Solve non-linear problem (12) to obtain $\frac{\partial T_{1}^{k}}{\partial n_{1}}$ on $I_{14} \cup I_{12}$ :

$$
\left\{\begin{array}{l}
-\nabla\left(k_{1} \nabla T_{1}^{k}\right)+\omega_{b} \rho_{b} c_{b} T_{1}^{k}=\omega_{b} \rho_{b} c_{b} T_{b} \quad \text { in } D_{1}, \\
-k_{1} \frac{\partial T_{1}^{k}}{\partial n_{1}}=h_{a m b}\left(T_{1}-T_{a m b}^{k}\right)+\sigma \varepsilon\left(\left(T_{1}^{k}\right)^{4}-T_{a m b}^{4}\right)+E \quad \text { on } \quad \Gamma_{c} \\
T_{1}^{k}=\mu_{k-1}^{1} \quad \text { on } \quad I_{14} \cup I_{12} .
\end{array}\right.
$$

- Solve linear problem (13) to obtain $T_{2}^{k}$ on $I_{12}$ and $\frac{\partial T_{2}^{k}}{\partial n_{2}}$ on $I_{23}$ :

$$
\left\{\begin{array}{l}
-\nabla\left(k_{2} \nabla T_{2}^{k}\right)+\omega_{b} \rho_{b} c_{b} T_{2}^{k}=\omega_{b} \rho_{b} c_{b} T_{b} \text { in } D_{2} \\
-k_{2} \frac{\partial T_{2}^{k}}{\partial n_{2}}=k_{1} \frac{\partial T_{1}^{k}}{\partial n_{1}} \text { on } I_{12} \\
T_{2}^{k}=\mu_{k-1}^{2} \text { on } I_{23} .
\end{array}\right.
$$

- Solve linear problem (14) to obtain $T_{3}^{k}$ on $I_{14} \cup I_{23}$ :

$$
\left\{\begin{array}{l}
-\nabla\left(k_{3} \nabla T_{3}^{k}\right)+\omega_{b} \rho_{b} c_{b} T_{3}^{k}=\omega_{b} \rho_{b} c_{b} T_{b} \quad \text { in } \quad D_{3} \cup D_{4}, \\
-k_{3} \frac{\partial T_{3}^{k}}{\partial n_{3}}=h_{b l}\left(T_{3}^{k}-T_{b l}\right) \quad \text { on } \Gamma_{s}, \\
-k_{3} \frac{\partial T_{3}^{k}}{\partial n_{3}}=k_{1} \frac{\partial T_{1}^{k}}{\partial n_{1}} \quad \text { on } \quad I_{14} \\
-k_{3} \frac{\partial T_{3}^{k}}{\partial n_{3}}=k_{2} \frac{\partial T_{2}^{k}}{\partial n_{2}} \quad \text { on } \quad I_{23} .
\end{array}\right.
$$

- Update:

$$
\begin{aligned}
& \left.\mu_{k}^{1}=\mu_{k-1}^{1}+\theta_{1}\left(T_{2}^{k}-\mu_{k-1}^{1}\right) \quad \text { on } \quad I_{12} \quad \text { and } \quad \theta_{1} \in\right] 0,1[\text {, } \\
& \left.\mu_{k}^{2}=\mu_{k-1}^{2}+\theta_{2}\left(T_{3}^{k}-\mu_{k-1}^{2}\right) \quad \text { on } \quad I_{14} \cup I_{23} \quad \text { and } \quad \theta_{2} \in\right] 0,1[.
\end{aligned}
$$

- Compute:

$$
\text { error }=\max \left(\left\|\mu_{k}^{1}-\mu_{k-1}^{1}\right\|,\left\|\mu_{k}^{2}-\mu_{k-1}^{2}\right\|\right) \quad k=k+1 .
$$

End while

\subsubsection{The eye divided into four sub-domains}

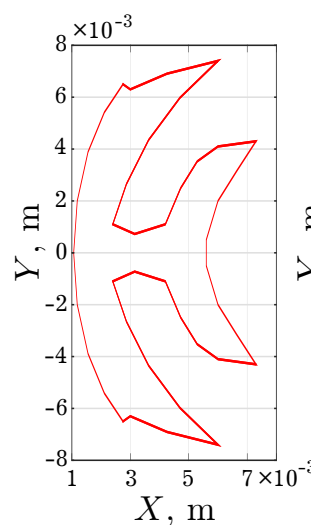

$D_{1}$

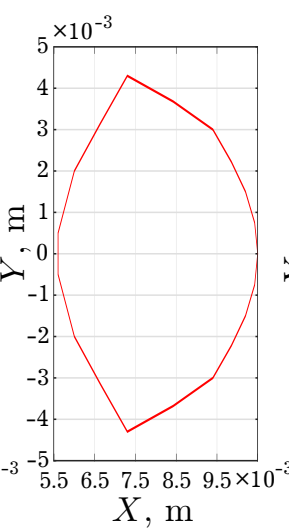

$D_{2}$

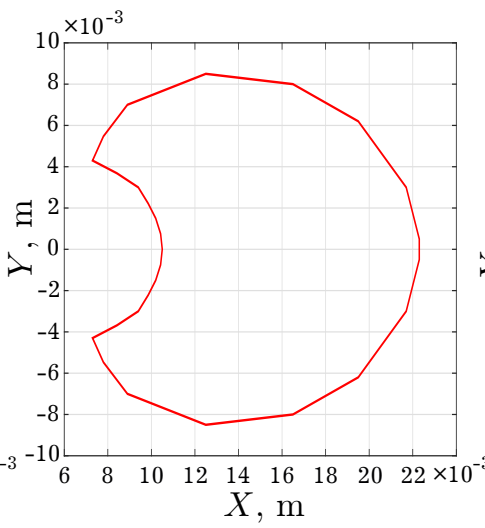

$D_{3}$

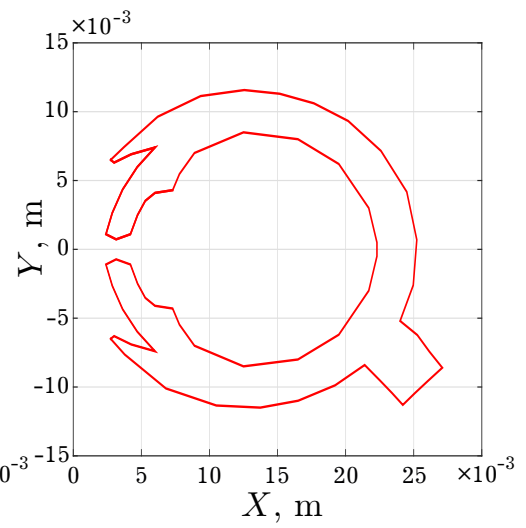

$D_{4}$

Fig. 5. The decomposition of the human eye into four sub-domains $D_{1}, D_{2}, D_{3}$ and $D_{4}$. 
In this part, the human eye is divided into four sub-domains $D_{1}, D_{2}, D_{3}$ and $D_{4}$ presented in Fig. 5. $I_{12}$ and $I_{14}$ are the interfaces between sub-domains $D_{1}$ and $D_{2}$ and $D_{1}$ and $D_{4} . I_{23}$ refers to the interface between sub-domains $D_{2}$ and $D_{3}$, while $I_{34}$ is the interface between sub-domains $D_{3}$ and $D_{4}$. In this case, the Dirichlet-Neumann algorithm solving problem (2)-(4) is written as in Algorithm 3.

Algorithm 3 Four non-overlapping subdomains
Tol, $\mu_{0}^{1}, \mu_{0}^{2}, \mu_{0}^{3}, k=1$, and error $=1$
While error $\geqslant$ Tol
- Solve non-linear problem (15) to obtain $\frac{\partial T_{1}^{k}}{\partial n_{1}}$ on $I_{14} \cup I_{12}$ :
\[ \left\{\begin{array}{l}-\nabla\left(k_{1} \nabla T_{1}^{k}\right)+\omega_{b} \rho_{b} c_{b} T_{1}^{k}=\omega_{b} \rho_{b} c_{b} T_{b} \text { in } D_{1}, \\ -k_{1} \frac{\partial T_{1}^{k}}{\partial n_{1}}=h_{a m b}\left(T_{1}^{k}-T_{a m b}\right)+\sigma \varepsilon\left(\left(T_{1}^{k}\right)^{4}-T_{a m b}^{4}\right)+E \text { on } \Gamma_{c}, \\ T_{1}^{k}=\mu_{k-1}^{1} \text { on } I_{14} \cup I_{12} .\end{array}\right. \]

- Solve linear problem (16) to obtain $T_{2}^{k}$ on $I_{12}$ and $\frac{\partial T_{2}^{k}}{\partial n_{2}}$ on $I_{23}$ :

$$
\left\{\begin{array}{l}
-\nabla\left(k_{2} \nabla T_{2}^{k}\right)+\omega_{b} \rho_{b} c_{b} T_{2}^{k}=\omega_{b} \rho_{b} c_{b} T_{b} \text { in } D_{2} \\
-k_{2} \frac{\partial T_{2}^{k}}{\partial n_{2}}=k_{1} \frac{\partial T_{1}^{k}}{\partial n_{1}} \text { on } I_{12} \\
T_{2}^{k}=\mu_{k-1}^{2} \text { on } I_{23} .
\end{array}\right.
$$

- Solve linear problem (17) to obtain $T_{3}^{k}$ on $I_{23}$ and $\frac{\partial T_{3}^{k}}{\partial n_{3}}$ on $I_{34}$ :

$$
\left\{\begin{array}{l}
-\nabla\left(k_{3} \nabla T_{3}^{k}\right)+\omega_{b} \rho_{b} c_{b} T_{3}^{k}=\omega_{b} \rho_{b} c_{b} T_{b} \text { in } D_{3}, \\
-k_{3} \frac{\partial T_{3}^{k}}{\partial n_{3}}=k_{2} \frac{\partial T_{2}^{k}}{\partial n_{2}} \text { on } I_{23}, \\
T_{3}^{k}=\mu_{k-1}^{3} \text { on } I_{34}
\end{array}\right.
$$

- Solve linear problem (18) to obtain $T_{4}^{k}$ on $I_{14} \cup I_{34}$ :

$$
\left\{\begin{array}{l}
-\nabla\left(k_{4} \nabla T_{4}^{k}\right)+\omega_{b} \rho_{b} c_{b} T_{4}^{k}=\omega_{b} \rho_{b} c_{b} T_{b} \quad \text { in } D_{4} \\
-k_{4} \frac{\partial T_{4}^{k}}{\partial n_{4}}=h_{b l}\left(T_{4}^{k}-T_{b l}\right) \quad \text { on } \Gamma_{s} \\
-k_{4} \frac{\partial T_{4}^{k}}{\partial n_{4}}=k_{1} \frac{\partial T_{1}^{k}}{\partial n_{1}} \quad \text { on } I_{14} \\
-k_{4} \frac{\partial T_{4}^{k}}{\partial n_{4}}=k_{3} \frac{\partial T_{3}^{k}}{\partial n_{3}} \quad \text { on } I_{34} .
\end{array}\right.
$$

- Update:

$$
\begin{array}{llll}
\mu_{k}^{1}=\mu_{k-1}^{1}+\theta_{1}\left(T_{2}^{k}-\mu_{k-1}^{1}\right) & \text { on } \left.\quad I_{12} \quad \text { and } \quad \theta_{1} \in\right] 0,1[, \\
\mu_{k}^{2}=\mu_{k-1}^{2}+\theta_{2}\left(T_{3}^{k}-\mu_{k-1}^{2}\right) & \text { on } \left.\quad I_{23} \quad \text { and } \quad \theta_{2} \in\right] 0,1[, \\
\mu_{k}^{3}=\mu_{k-1}^{3}+\theta_{3}\left(T_{4}^{k}-\mu_{k-1}^{3}\right) & \text { on } \left.\quad I_{14} \cup I_{34} \quad \text { and } \quad \theta_{3} \in\right] 0,1[.
\end{array}
$$

- Compute:

$$
\text { error }=\max \left(\left\|\mu_{k}^{1}-\mu_{k-1}^{1}\right\|,\left\|\mu_{k}^{2}-\mu_{k-1}^{2}\right\|,\left\|\mu_{k}^{3}-\mu_{k-1}^{3}\right\|\right), \quad k=k+1 .
$$

End while

The resolution of all non-linear problems in all algorithms is done using a non-linear modified Newton algorithm. 


\section{Results and discussion}

In this section, to confirm the performance of our method, we performed synthetic tests in which we used application examples where the analytic expression of the solution is known then real experiments have been carried out using data reported in the literature.

\subsection{Synthetic tests}

In the first set of tests, we used an example of the problem (1)-(4) where the analytical expression of the solution is $T_{e x}(x, y)=\cos (x+y)$, and $k(x, y)=\exp (-x-y)$. We have in Table 2 , the errors between approximated solutions $T_{n u m}$ and analytical solution $T_{e x}$ on the cornea and the sclera, respectively.

Table 2. Error between the analytical solution $T_{e x}$ and the approached solution $T_{n u m}$ and error between the analytical normal flux $Q_{e x}$ and the approched normal flux $Q_{n u m}$ on the Cornea and Sclera.

\begin{tabular}{|c|c|c|c|c|}
\hline \multirow{2}{*}{ Method } & \multicolumn{2}{|c|}{$\mid T_{e x}-T_{n u m} \|_{L^{\infty}\left(\Gamma_{c}\right)}$} & \multicolumn{2}{|c|}{$\mid Q_{e x}-Q_{n u m} \|_{L^{\infty}\left(\Gamma_{c}\right)}$} \\
\hline & Cornea & Sclera & Cornea & Sclera \\
\hline DRBEM & $8.18 \times 10^{-6}$ & $8.78 \times 10^{-6}$ & $4.45 \times 10^{-5}$ & $8.78 \times 10^{-6}$ \\
\hline Algorithm 1 & $1.63 \times 10^{-6}$ & $7.39 \times 10^{-7}$ & $2.95 \times 10^{-4}$ & $7.39 \times 10^{-7}$ \\
\hline Algorithm 2 & $6.39 \times 10^{-6}$ & $1.38 \times 10^{-6}$ & $2.81 \times 10^{-5}$ & $1.38 \times 10^{-6}$ \\
\hline Algorithm 3 & $1.16 \times 10^{-6}$ & $2.18 \times 10^{-6}$ & $3.09 \times 10^{-5}$ & $2.18 \times 10^{-6}$ \\
\hline
\end{tabular}

\subsection{Experiments with real data}

The main contribution of this work is to present a $2 \mathrm{D}$ model of heat distribution in human eye using dual reciprocity boundary element method in conjunction with domain decomposition method. We performed real experiments using parameters reported in Table 1.

\subsubsection{Dual reciprocity boundary element method without domain decomposition}

The heat distribution on the corneal surface is shown in Fig. 6(left), where the lowest temperature is $33.8188^{\circ} \mathrm{C}$ and it is located at the center of the cornea, the highest temperature $36.9310^{\circ} \mathrm{C}$ occurs at the optic nerve where the blood vessels are acting as a heating source. Figure6(right) plots the temperature variation along papillary axis. Figure 7 presents the heat flux distribution on the corneal surface.
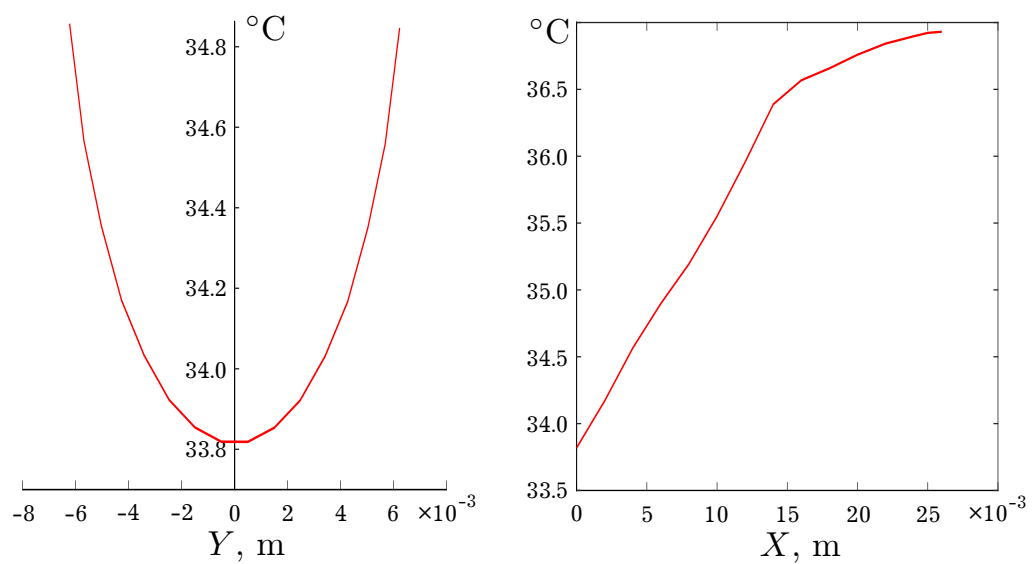

Fig. 6. Temperature $\left({ }^{\circ} \mathrm{C}\right)$ on the corneal surface (left) and on the papillary axis (right) obtained by DRBEM without domain decomposition.

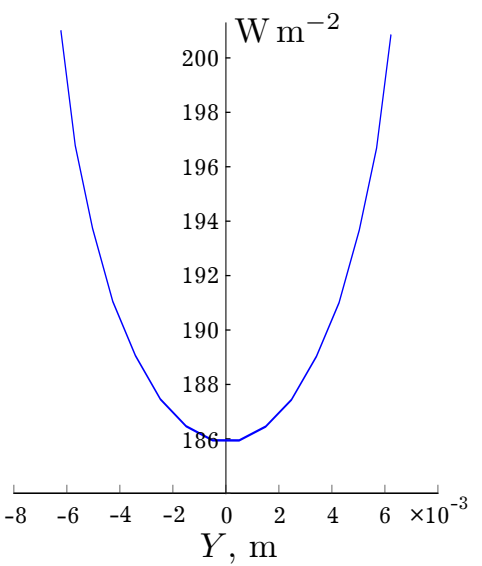

Fig. 7. Normal heat flux on the corneal surface $\left(\mathrm{W} \mathrm{m}^{-2}\right)$ calculated by DRBEM without domain decomposition. 


\subsubsection{Domain decomposition method: Two sub-domains}

In this section, we decomposed the human eye into two disjoint sub-domains $D_{1} \cup D_{2}$ and $D_{3} \cup D_{4}$, we used the Dirichlet-Neumann algorithm to solve (2)-(4). In Fig. 8(left), the lowest temperature $33.7974^{\circ} \mathrm{C}$ is located in the center of the cornea. The temperature increases gradually as one approaches the sclera and the optic nerve as shown in Fig. 8(right). Fig. 9 plots the heat flux on the corneal surface.
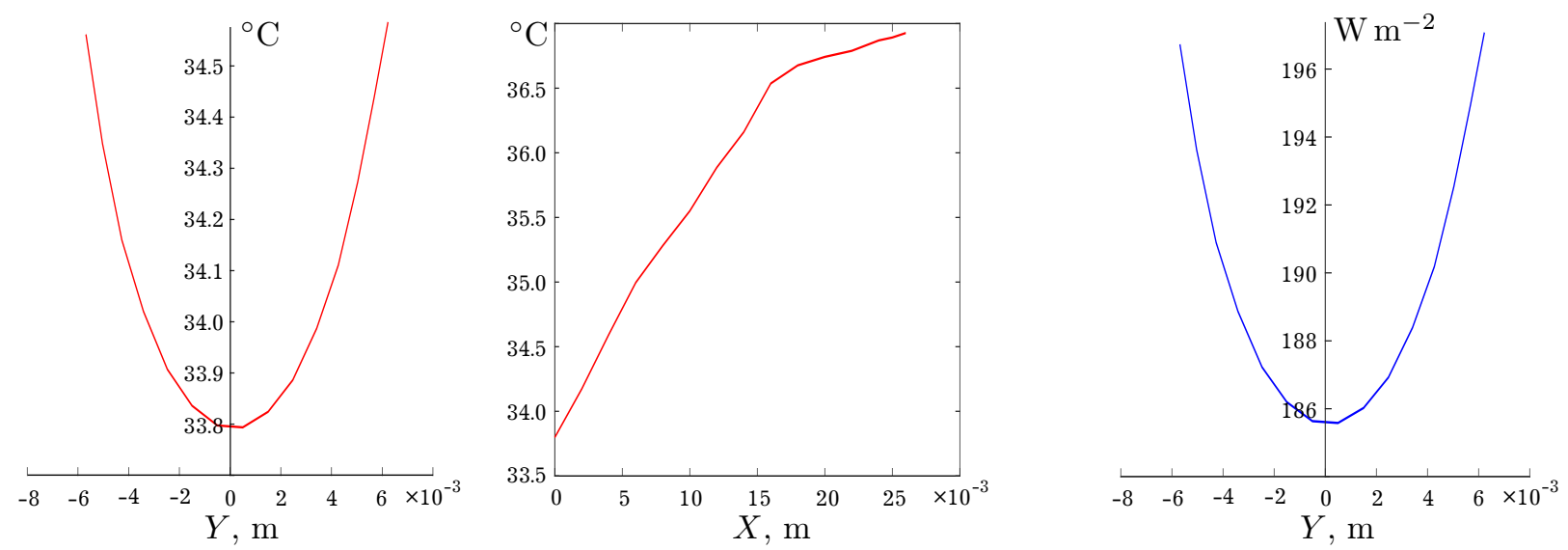

Fig. 8. Temperature $\left({ }^{\circ} \mathrm{C}\right)$ on the corneal surface (left) and on the Fig. 9. Normal heat flux on the corneal papillary axis (right) obtained by Algorithm 1. surface $\left(\mathrm{W} \mathrm{m}^{-2}\right)$ calculated byAlgorithm 1 .

\subsubsection{Domain decomposition method: Three sub-domains}

In this part, we partitioned the human eye into three sub-domains $D_{1}, D_{2}$, and $D_{3} \cup D_{4}$, we used the Dirichlet-Neumann algorithm to solve (2)-(4). Fig. 10(left) shows heat distribution on the corneal surface where the lowest temperature, $33.7787^{\circ} \mathrm{C}$, is located at the center of the cornea. The highest temperatures occur at the optic nerve and the sclera. Fig. 10(right) plots the heat variation along papillary axis. Fig. 11 lays out the heat flux distribution on the corneal surface.
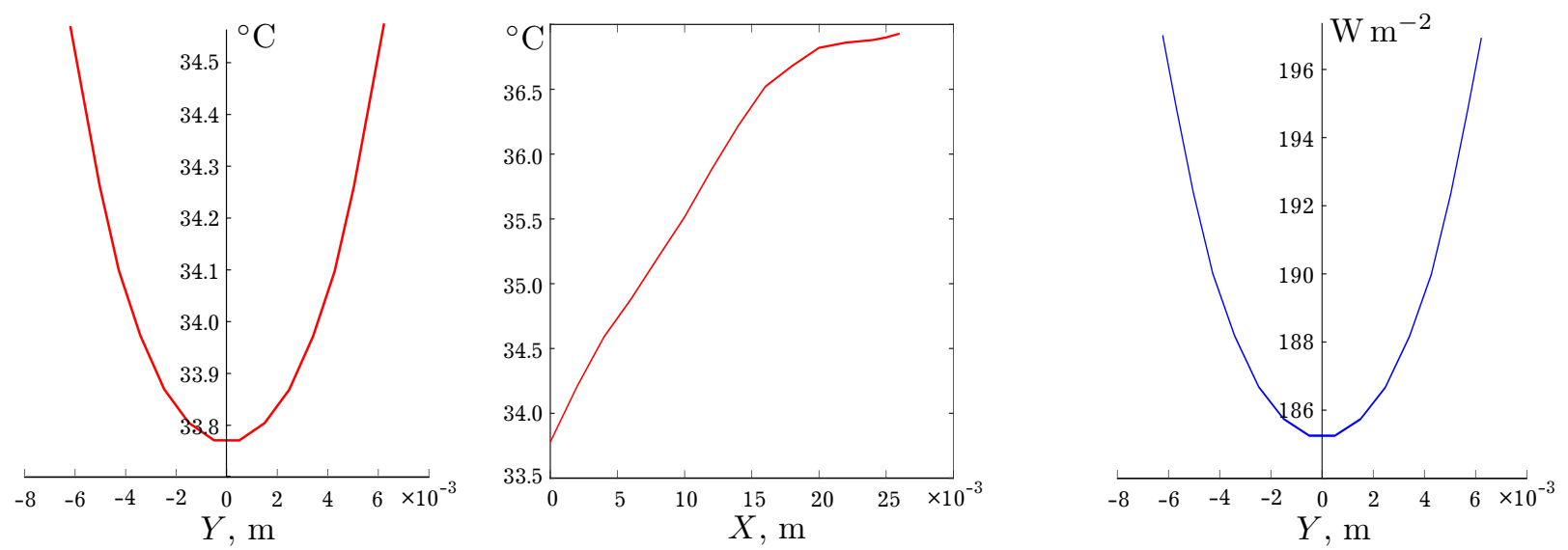

Fig. 10. Temperature $\left({ }^{\circ} \mathrm{C}\right)$ on the corneal surface (left) and on Fig. 11. Normal heat flux on the corneal the papillary axis (right) obtained by Algorithm 2. surface $\left(\mathrm{W} \mathrm{m}^{-2}\right)$ calculated byAlgorithm 2 .

\subsubsection{Domain decomposition method: Four sub-domains}

In the last numerical simulation, we subdivided the human eye into four sub-domains $D_{1}, D_{2}, D_{3}$, and $D_{4}$. Similarly, we solved problem (2)-(4) using Dirichlet-Neumann algorithm. Fig. 12(left) and Fig. 12 (right) show that the numerical value of the temperature at the center of the cornea is $33.7710^{\circ} \mathrm{C}$ and the temperature increases as we go away from the cornea. 

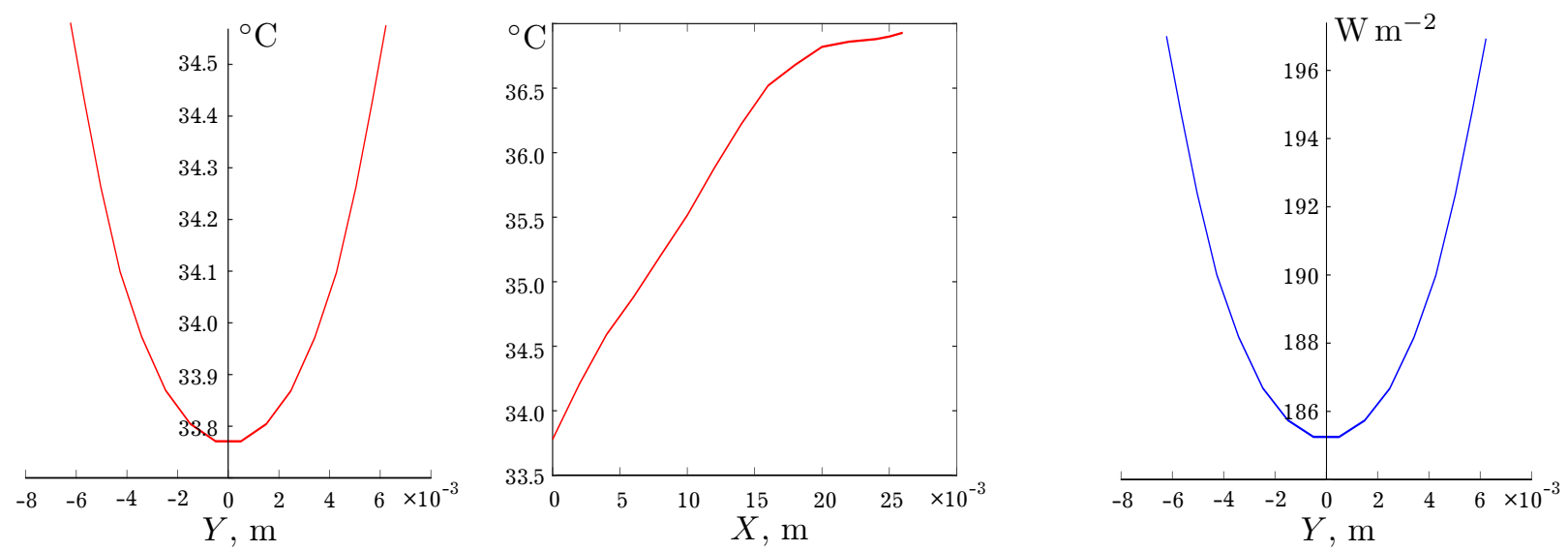

Fig. 12. Temperature $\left({ }^{\circ} \mathrm{C}\right)$ on the corneal surface (left) and on Fig. 13. Normal heat flux on the corneal the papillary axis (right) obtained by Algorithm 3. surface $\left(\mathrm{W} \mathrm{m}^{-2}\right)$ calculated byAlgorithm 3 .

Table 3. Comparison of values of the temperature at the center of the corneal surface, obtained by the proposed methods and the values obtained by previous numerical and experimental studies.

\begin{tabular}{|c|c|c|}
\hline Method & Temperature $\left({ }^{\circ} \mathrm{C}\right)$ & Reference \\
\hline DRBEM without DD & 33.8188 & Present work \\
\hline Algorithm 1 & 33.7974 & Present work \\
\hline Algorithm 2 & 33.7787 & Present work \\
\hline Algorithm 3 & 33.7710 & Present work \\
\hline Boundary element method & 33.65 & Ean-Hin Ooi et al [14] \\
\hline Finite element method & 33.68 & E. Y. K. Ng et al [13] \\
\hline Finite element method & 33.25 & Scott $[18]$ \\
\hline Finite element method & 33.713 & Amara [1] \\
\hline Experimental method: Infra-red & 34.80 & Mapstone [11] \\
\hline Experimental method: Infra-red & 34.50 & Rysa et al [17] \\
\hline Experimental method: Contact probe & 33.67 & Horven et al [9] \\
\hline Experimental method: Infra-red & 33.40 & Fielder et al $[6]$ \\
\hline Experimental method: heat flow & 34.50 & Martin et al [12] \\
\hline
\end{tabular}

All the methods that have been applied in this study, give values of the temperatures at the center of the cornea between $33.7710^{\circ} \mathrm{C}$ and $33.8188^{\circ} \mathrm{C}$. It is clear from Table 3 that there is a good agreement between our results and past experimental and numerical results. The temperature on the papillary axis is noticed to increase from it lowest value at the center of the corneal surface to a higher temperature at the sclera.

\section{Conclusion}

In this work, we formulate the dual reciprocity boundary element method to find heat distribution in the 2D model of the human eye. At first, we considered the human eye as one domain, then we applied a non-overlapping Dirichlet-Neumann domain decomposition method by decomposing the human eye into two sub-domains then three sub-domains and in a the last simulation to four subdomains. Comparing the obtained results with previous numerical and experimental studies our 2D model is an accurate representation of heat distribution in the human eye. The presented model can be used to predict the heat distribution in the case of a tumor in the human eye.

[1] Amara E. H. Numerical investigations on thermal effects of laser ocular media interaction. International Journal of Heat and Mass Transfer. 38 (13), 2479-2488 (1995). 
[2] Danumjaya P., Pani A.K. A block monotone domain decomposition algorithm for nonlinear singularly perturbed parabolic problem. International Journal of numerical analysis and modeling. 3 (2), 211-231 (2006).

[3] Charles M. W., Brown N. Dimensions of the human eye relevant to radiation protection (dosimetry). Phys. Med. Biol. 20 (2), 202-218 (1975).

[4] Cicekli U. Computational model for heat transfer in the human eye using the finite element method. M. Sc. Thesis, Department of Civil and Environmental Engineering, Louisiana State University (2003).

[5] Efron N., Young G., Brennan N. A. Ocular surface temperature. Current Eye Research. 8 (9), 901-906 (1989).

[6] Fielder A. R., Winder A.F., Sheridaidah G. A. K., Cooke E. D. Problems with corneal arcus. Transactions of the Ophtalmological Societies of the United Kingdom. 101 (1), 22-26 (1981).

[7] Fontana S. T., Brubaker R. F. Volume and DOF the anterior chamber of the normal aging human eye. Arch. Ophthalmol. 98 (10), 1803-1808 (1980).

[8] Gokul K., Dil Bahadur G., Pushpa R. FEM approach for transient heat transfer in human eye. Appl. Math. 4 (10B), 30-36 (2013).

[9] Horven I., Larsen C. T. Contact probe for corneal temperature measurements. Acta Ophthalmologica. 53 (6), 856-862 (1975).

[10] Lagendijk J. J. A mathematical model to calculate temperature distributions in human and rabbit eyes during hyperthermic treatment. Physics in Medicine and Biology. 27, 1301-1311 (1982).

[11] Mapstone R. Measurement of corneal temperature. Experimental Eye Research. 7, 237-243 (1968).

[12] Martin D. K., FattI. The presence of a contact lens induces a very small increase in the anterior corneal surface temperature. Acta Ophthalmologica. 64 (5), 512-518 (1986).

[13] Ng E. Y. K., Ooi E. H. FEM simulation of the eye structure with bioheat analysis. Computer Methods and Programs in Biomedicine. 82 (3), 268-276 (2006).

[14] Ooi E. H., Ang W. T., Ng E. Y.K. Bioheat transfer in the human eye: A boundary element approach. Engineering Analysis with Boundary Elements. 31 (6), 494-500 (2007).

[15] Pennes H. H. Analysis of tissue and arterial blood temperatures in the resting foream. J. Appl. Physiol. 1 (2), 93-122 (1948).

[16] Purslow C., Wolffsohn J.S., Santodomingo-Rubido J. The effect of contact lens wear on dynamic ocular surface temperature, Contact Lens and Anterior Eye. Contact Lens \& Anterior Eye. The Journal of The British Contact Lens Association. 28 (1), 29-36 (2005).

[17] Rysa P., Sarvaranta J. Thermography of the eye during cold stress. Acta Ophthalmologica. 123, 234-239 (1973).

[18] Scott J. A. A finite element model of heat transport in the human eye. Physics in Medicine and Biology. 33 (2), 227-241 (1988). 


\title{
Моделювання розподілу тепла в людському оці за допомогою дуального розривного методу граничних елементів та методу декомпозиції для областей без перекриття
}

\author{
Ахмедоу Бамба С., Еллабиб А., Ел Мадкоури А. \\ Університет Каді Айяд, Лабораторія прикладної математики та обчислювальної техніки, \\ Факультет науки і техніки, \\ Авеню Абделькрим Ель-Хаттабі Б. П. 549, Марракеш, Марокко
}

У цій роботі досліджено чисельне двовимірне моделювання розподілу тепла в людському оці. Для отримання розподілу тепла в людському оці застосовується дуальний метод граничних елементів (DRBEM). Метод Діріхле-Ноймана для областей без перекриття в поєднанні з DRBEM використовується для пошуку більш точного зображення розподілу тепла в людському оці, яке подається як дві, три та чотири підобласті. Отримані результати порівнюються з літературними експериментальними та чисельними дослідженнями. Моделювання запропонованих алгоритмів з достатньою точністю описує розподіл тепла в людському оці.

Ключові слова: розподіл тепла, людсъке око, дуальний метод, метод граничних елементів. 